\title{
К исследованию годичной динамики температуры почв Хибинского горного массива
}

\author{
Штабровская И.М., Зенкова И.В. \\ Институт проблем промышленной экологии Севера КНЦ РАН, Anamumbl, ishtabrovskaya@mail.ru
}

\begin{abstract}
Аннотация. В статье даётся обзор по годичной динамике 4 участков, расположенных на сходной географической широте: склон северо-западной экспозиции и склон юго-восточной экспозиции горы Вудъяврчорр, на котором исследовались 2 горных пояса: горной тундры и высокогорное плато. Цель исследований состояла в характеристике температурных показателей наиболее биологически активного горизонта горных почв Хибин - органогенного или подстилки - с учетом факторов высотной поясности почвенно-растительного покрова и экспозиции горных склонов. Сравнивались максимальные и минимальные среднесуточные и среднегодовые температуры, а также суммы эффективных и отрицательных температур между склонами разной экспозиции и между участками одноименных поясов с использованием $t$-критерия Стьюдента.
\end{abstract}

Ключевые слова: Хибинский массив, высотный пояс, высотная зональность.

\section{On the study of annual dynamics of temperature of the Khibiny massif soils}

Shtabrovskaya I.M. ${ }^{1}$, Zenkova I. V. ${ }^{2}$

\begin{abstract}
The article provides an overview of the annual dynamics of 4 plots located at the similar geographical latitude, i.e. the slope of the northwestern exposure and the slope of the southeastern exposure of the Vudyavrchorr mountain, on which 2 mountainous belts were investigated, i.e. mountain tundra and alpine plateau. The purpose of the research is to characterize the temperature indicators of the most biologically active horizon of the Khibiny mountain soils - organogenic or litter - taking into account the factors of the altitudinal zonation of the soil and vegetation cover and the exposure of the mountain slopes. The maximum and minimum average daily and average annual temperatures were compared, as well as the sum of effective and negative temperatures between the slopes of different exposures and between sections of the same-named belts using Student's $t$-test.
\end{abstract}

Key words: Khibiny mountains, altitudinal belt, altitudinal zonation.

\section{Введение}

В докладе представлены результаты исследований, полученные авторами в полевой сезон 2017-2018 гг. на участках с разной экспозицией склонов г. Вудъяврчорр. В частности, был определен общегодовой ход температур в подстилках высокогорных поясов Хибин. Установлено, что годовая динамика среднесуточной температуры подстилок определятся динамикой температуры атмосферного. Выделили три фактора, которые оказывают дифференцирующее влияние на температурный режим горных подстилок: «сезонность», «экспозиция горного склона» и «высотная поясность».

\section{объекты и методы исследования}

В полевой сезон 2017-2018 гг. были выполнены работы по закладке термодатчиков в подстилку на глубину 5 см горы Вудъяврчорр на 4 горных участках разной экспозиции склонов (табл. 1), автоматические регистраторы температуры - термохроны серии ТPB-2 с предельным диапазоном измерений от -25 до $+40{ }^{\circ} \mathrm{C}$. Термохроны фиксировали температуру в подстилках каждые 2 часа (внутрисуточная динамика).

\section{Результаты}

На протяжении периода измерений с 20.09.2017 по 24.06.2018 Tcym 5 см изменялась от $-1.8 \ldots .0$ до $+10.8 \ldots+14.5^{\circ} \mathrm{C}$ (рис. 1). Для горно-тундрового пояса ущелья Скальное было установлено достоверное влияние экспозиции склонов на годовой ход температур: для $T_{\text {лиш-юв }}$ с 25 октября наблюдается снижение температур ниже $T c y m_{c p}=0^{\circ} \mathrm{C}$, при этом обратный ве- 
сенний переход через порог 0 начинался с 15 мая. В подстилках $T_{\text {лиш-сз }}$ на протяжении всего года $T_{c y m_{c p}}$ не опускается ниже 0 , но прогревание происходит в меньшей степени после схода снега (с 15 мая) и на протяжении лета.

Таблица 1. Характеристика 4 исследованных горных участков разной экспозиции склонов г. Вудъяврчорр.

Table 1. Characteristics of 4 studied mountain areas of different exposure slopes of Mt. Vudyavrchorr.

\begin{tabular}{|c|c|c|c|c|}
\hline \multirow{2}{*}{ Участок } & \multicolumn{2}{|c|}{ Высокогорное плато } & \multicolumn{2}{c|}{ Ущелье Скальное } \\
\cline { 2 - 5 } & $\begin{array}{c}\text { Тундра } \\
\text { лишайниковая }\end{array}$ & $\begin{array}{c}\text { Тундра } \\
\text { злаковая }\end{array}$ & $\begin{array}{c}\text { Тундра } \\
\text { лишайниковая } \\
\text { на склоне }\end{array}$ & $\begin{array}{c}\text { Тундра } \\
\text { лишайниковая } \\
\text { на склоне }\end{array}$ \\
\hline $\begin{array}{c}\text { Экспозиция } \\
\text { склона }\end{array}$ & \multicolumn{2}{|c|}{ Плато } & С3 & ЮВ \\
\hline $\begin{array}{c}\text { Аббревиатура } \\
\text { Горно-растительный } \\
\text { пояс }\end{array}$ & $T_{\text {лиш }}$ & $T_{\text {злАк }}$ & $T_{\text {лиш-сз }}$ \\
\hline Высота над ур. м., м & 1021 & 1023 & \multicolumn{2}{|c|}{ Горно-тундровый } \\
\hline
\end{tabular}

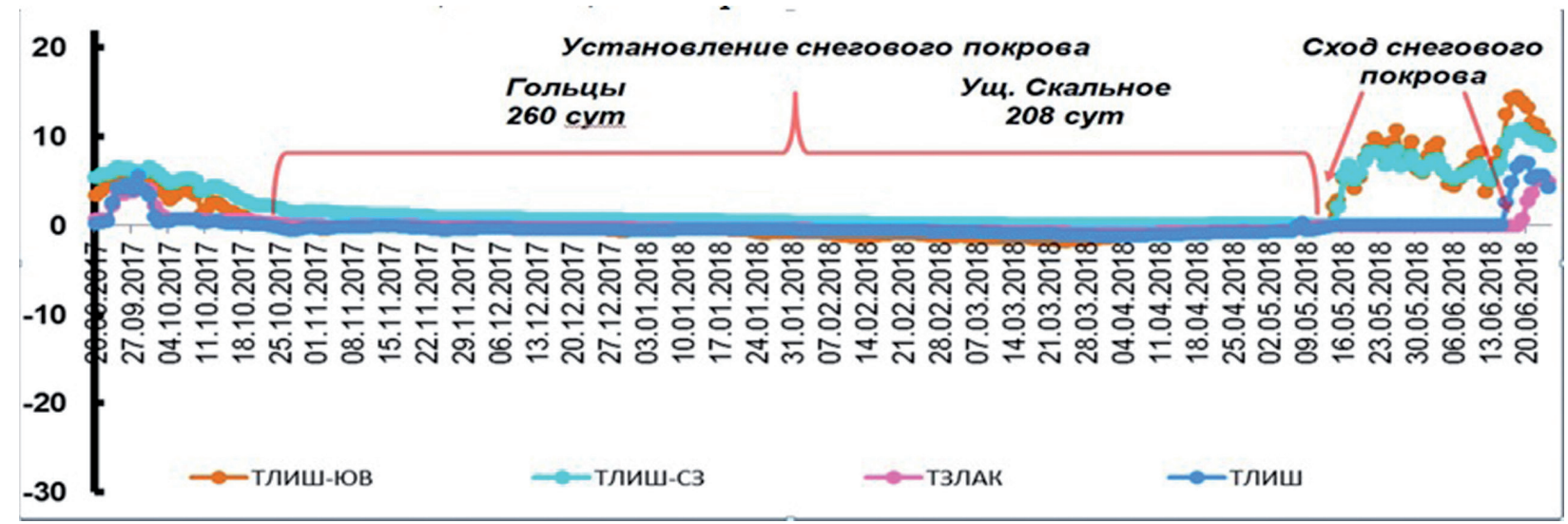

Рис. 1. Динамика среднесуточной температуры подстилок $\left(\mathrm{Tcyтcp,}{ }^{\circ} \mathrm{C}\right)$ на площадке ущелье Скальное и гольцового пояса с июня 2017 по июль 2018 г.

Fig. 1. Dynamics of the average daily temperature of litter (Tdayav, ${ }^{\circ} \mathrm{C}$ ) at the site of the Skalnoe gorge and alpine belt from June 2017 to July 2018.

\begin{tabular}{|c|c|c|c|c|}
\hline \multirow{2}{*}{ Координаты } & $67^{\circ} 38^{\prime} 25,6^{\prime \prime}$ & $67^{\circ} 38^{\prime} 23,7^{\prime \prime}$ & $67^{\circ} 36^{\prime} 01,8^{\prime \prime}$ & $67^{\circ} 35^{\prime} 56,9^{\prime \prime}$ \\
& $33^{\circ} 36^{\prime} 43,4^{\prime \prime}$ & $33^{\circ} 36^{\prime} 43,0^{\prime \prime}$ & $33^{\circ} 36^{\prime} 16,6^{\prime \prime}$ & $33^{\circ} 35^{\prime} 42,4^{\prime \prime}$ \\
\hline
\end{tabular}

Установление снегового покрова на площадке гольцового пояса наблюдалось на 13 суток раньше, чем в горно-тундровом поясе ущелье Скальное, а весенний сход снега (с 14 июня) почти на месяц позже. Таким образом, общая продолжительность снегового покрова была больше почти на 1.5 месяца. Отличием зимней динамики участков на плато является то, что $T c y m_{c p}$ стабильно ниже нуля.

Для всех 4 исследованных горных участков была установлена достоверная корреляция динамики среднесуточной температуры подстилок и атмосферного воздуха. Коэффициент корреляции был выше для лучше прогреваемой подстилки тундры лишайниковой на склоне С3 экспозиции (0.72) по сравнению с тундрой лишайниковой на склоне ЮВ экспозиции (0.69) и меньшим для тундровых подстилок высокогорного плато $0.50\left(T_{\text {лиш }}\right)$ и $0.42\left(T_{\text {злАк }}\right)$ (рис. 2). Стоит отметить, что корреляция с температурой воздуха выражена только в те месяцы, когда отсутствует снеговой покров.

Как наименьшие, так и наибольшие значения Тгод ср наблюдались в подстилках горнотундрового пояса на склонах встречной экспозиции ущелье Скальное (рис. 3). Различия среднелетних значений температуры подстилок на исследованных нами участках за период исследования 280 


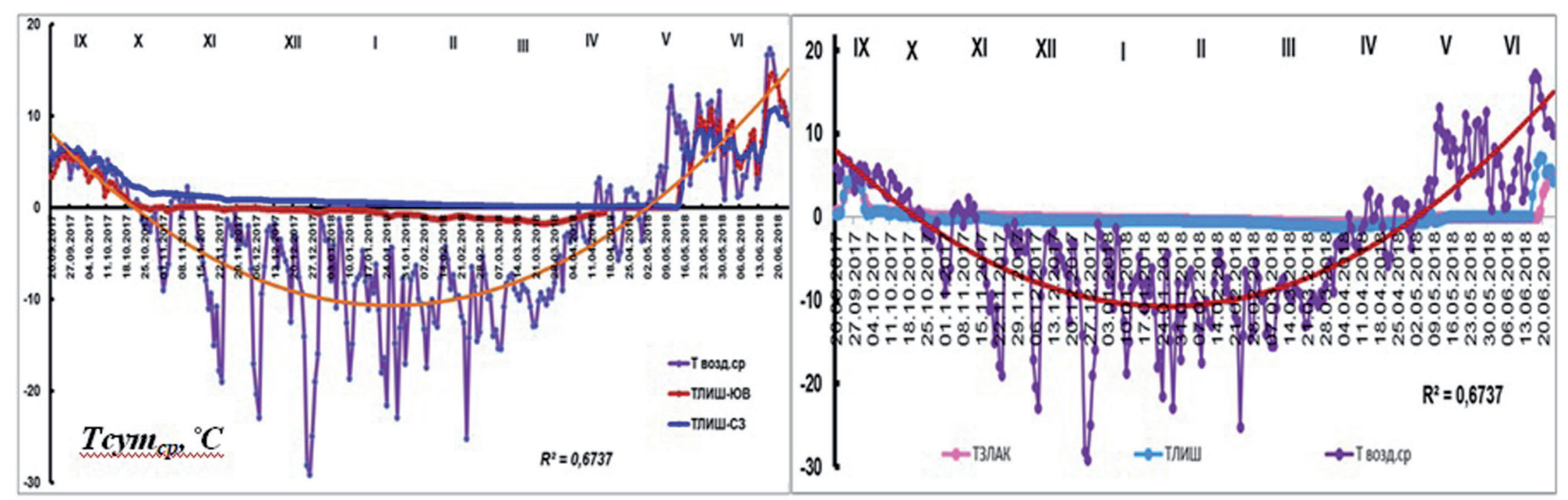

Рис. 2. Корреляция динамики температуры подстилок и атмосферного воздуха на площадке ущелье Скальное и гольцового пояса с июня 2017 по июль 2018 г.

Fig. 2. The correlation of the temperature dynamics of litter and atmospheric air at the site of the Skalnoe gorge and the alpine belt from June 2017 to July 2018.

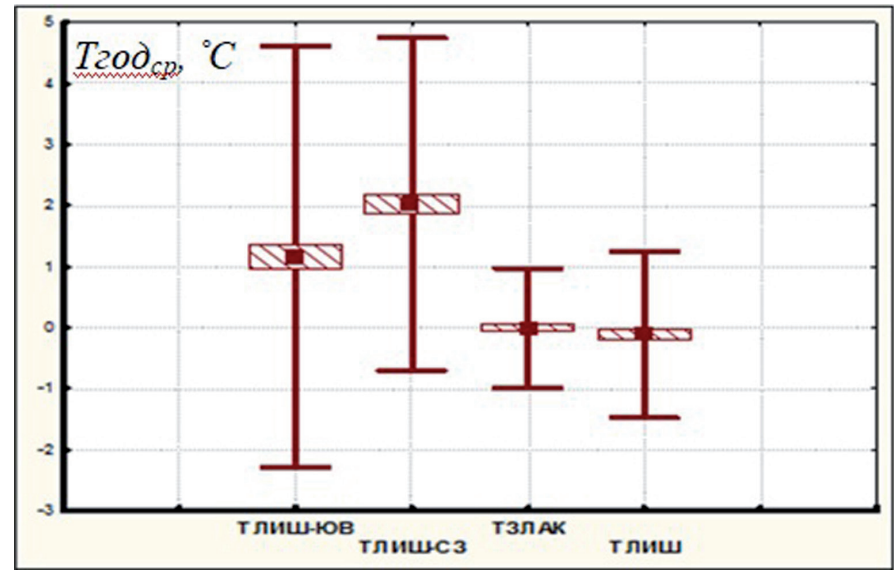

Рис. 3. Среднегодовые значения температуры подстилки на исследованных участках горнотундрового и гольцового поясов (Тгод ср за период 280 сут, $\left.{ }^{\circ} \mathrm{C}\right)$.

Fig. 3. The average annual temperature of litter in the studied areas of the mountain-tundra and alpine belts (Tyears ${ }_{\text {av }}$ for a period of 280 days, ${ }^{\circ} \mathrm{C}$ ).

Таблица 2. Значения $t$-критерия Стьюдента при сравнении среднегодовой температуры подстилок $\left(\right.$ Тгод $\left._{c p}\right)$ между участками горно-тундрового и гольцового поясов.

Table 2. The values of the Student's t-test when comparing the average annual temperature of litter (Tyears ${ }_{\text {av }}$ ) between the sections of the mountain-tundra and alpine belts.

\begin{tabular}{|c|c|c|c|c|c|c|}
\hline & $T_{\text {лиш }} / T_{\text {ЗлАК }}$ & $T_{\text {лиш_сз/1 }} T_{\text {ЗлАК }}$ & $\mathrm{T}_{\text {лишсз }} / \mathrm{T}_{\text {лиш }}$ & $T_{\text {ЛИш-юв }} / T_{\text {ЗлАК }}$ & $\mathrm{T}_{\text {лишююв }} / \mathrm{T}_{\text {лиш }}$ & $T_{\text {лиш-юв }} / T_{\text {лиш-сз }}$ \\
\hline$T_{s t}$ & 1.01 & 11.67 & 11.65 & 5.45 & 5.73 & 3.24 \\
\hline
\end{tabular}

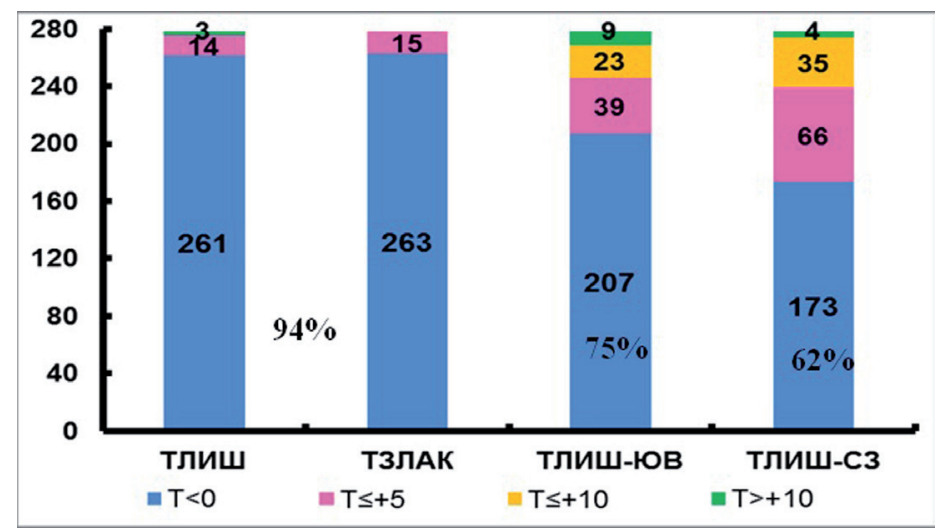

Рис. 4. Число дней с $T c y m_{c p} \leq 0^{\circ} \mathrm{C}, 0 \ldots+5^{\circ} \mathrm{C}$, $+5 \ldots+10^{\circ} \mathrm{C},>+10^{\circ} \mathrm{C}$ в подстилках на исследованных участках горно-тундрового и гольцового поясов (за период 280 сут.).

Fig. 4. The number of days with Tday ${ }_{a v} \leq 0^{\circ} \mathrm{C}$, $0 \ldots+5^{\circ} \mathrm{C},+5 \ldots+10^{\circ} \mathrm{C},>+10^{\circ} \mathrm{C}$ in the litter on the studied areas of the mountain-tundra and alpine belts (for a period of 280 days). 


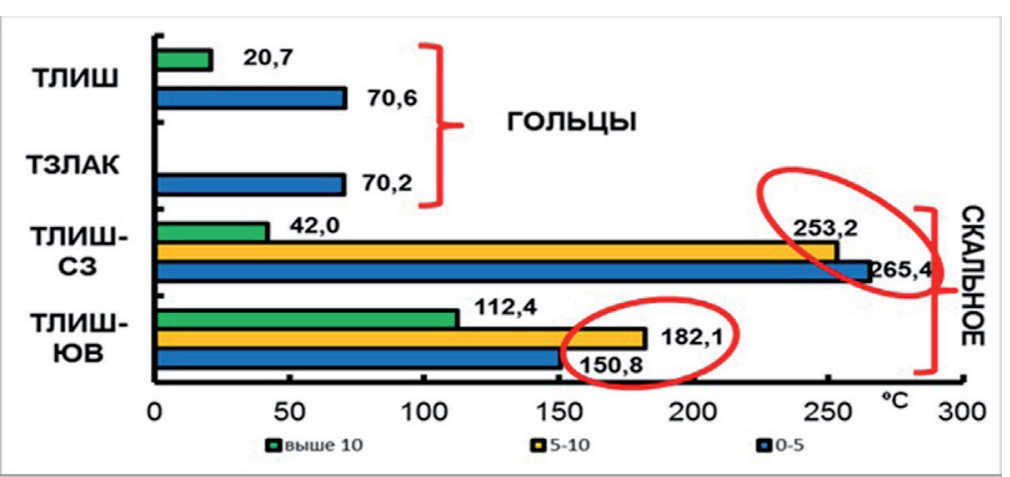

Рис. 5. Сумма среднесуточных температур $\left(\sum \operatorname{Tcym}_{c p},{ }^{\circ} \mathrm{C}\right) 0 \ldots+5^{\circ} \mathrm{C},+5 \ldots+10^{\circ} \mathrm{C}$, $>+10^{\circ} \mathrm{C}($ n сут $=280)$.

Fig. 5. The sum of average daily temperatures $0 \ldots+5^{\circ} \mathrm{C},+5 \ldots+10^{\circ} \mathrm{C},>+10^{\circ} \mathrm{C}$ $(\mathrm{n}$ days $=280)$.

суток были достоверны (табл. 2). Различия в вариабельности температуры между склонами встречной экспозиции зависели преимущественно от минимальных среднесуточных значений.

Сравнивая суммы положительных температур горных подстилок и число суток с $\operatorname{Tcym}_{c p} \leq 0^{\circ} \mathrm{C}, 0 \ldots+5^{\circ} \mathrm{C},+5 \ldots+10^{\circ} \mathrm{C},>+10^{\circ} \mathrm{C}$, выявили, что в годовой динамике преобладают дни с отрицательными температурами подстилок. Таким образом, число дней с Tcym $\leq 0^{\circ} \mathrm{C}$ на высокогорного плато: 261-263 против 173-207 в тундрах на склонах ущелья. Теплые дни с эффективными температурами $>+5^{\circ} \mathrm{C}$ и $>+10^{\circ} \mathrm{C}$ на высокогорном плато практически отсутствуют (рис. 4).

Стоит отметить, что сумма положительных температур за 280 суток не превысила $100^{\circ} \mathrm{C}$ на высокогорном плато и была больше в горной тундре ущелье Скальное: $445^{\circ} \mathrm{C}$ на склоне ЮВ экспозиции и $560^{\circ} \mathrm{C}$ на склоне С3 экспозиции (рис. 5).

\section{Выводы}

Таким образом, был определен общегодовой ход температур в подстилках высокогорных поясов Хибин: в горной тундре на склонах на высоте 500 метров и на плато на максимальных высотных отметках преобладают дни с отрицательной или околонулевой температурой подстилок. Число этих дней совпадает с продолжительностью залегания снегового покрова (260 сут. на плато и 208 сут. на склонах). Наиболее теплые месяцы годового цикла - июль и август ( 30 сут. на плато и $\sim 40$ сут. на склонах), когда среднесуточные температуры подстилок прогреваются до $+15 \ldots+22^{\circ} \mathrm{C}$. Среднегодовые температуры подстилок составляют $+1 \ldots+2{ }^{\circ} \mathrm{C}$ в поясе горной тундры на склонах и околонулевые-отрицательные значения на высокогорном плато. Годовые суммы положительных температур в этих поясах не превышают 500 и $100^{\circ} \mathrm{C}$ соответственно. При этом, годовая динамика среднесуточной температуры подстилок определятся динамикой температуры атмосферного воздуха. Эта зависимость выражена сильнее для тундры лишайниковой на склоне С3 экспозиции (0.72) по сравнению с тундрой лишайниковой на склоне ЮВ экспозиции (0.69) и в меньшей степени - для подстилок высокогорного плато: $0.50\left(T_{\text {лиш }}\right)$ и $0.42\left(T_{\text {зляк }}\right)$. Обобщая полученные данные по температурным показателям и их годовой динамике в экосистемах горы Вудъяврчорр, можно выделить три фактора, оказывающие дифференцирующее влияние на температурный режим горных подстилок: «сезонность», «экспозиция горного склона» и «высотная поясность».

Влияние фактора высотной поясности проявляется:

- в осенне-зимний период - в большей продолжительности снегового покрова и большем количестве дней с отрицательными среднесуточными температурами подстилки в гольцах на плато по сравнению с тундрами на склонах;

- в летний период - в более высоких максимальных значениях температуры подстилки в гольцах, которые, однако, наблюдаются меньшее количество дней, в результате чего сумма положительных температур выше в тундре, чем в гольцах.

Достоверное влияние фактора экспозиции горных склонов в пределах горно-тундрового пояса проявляется: в лучшем прогреве подстилок ЮВ склона в весенне-летний период (до $+14.5^{\circ} \mathrm{C}$ против $+10.8^{\circ} \mathrm{C}$ на С 3 склоне) и в более низких температурах подстилки ЮВ склона в осенне-зимний период (до $-1.79^{\circ} \mathrm{C}$ против $+0.04{ }^{\circ} \mathrm{C}$ на $\mathrm{C} 3$ склоне). Годовая сумма положительных температур выше на склоне С3 экспозиции по сравнению с ЮВ склоном: $560^{\circ} \mathrm{C}$ против $445^{\circ} \mathrm{C}$. 